\title{
Sports, recreation and employment following spinal cord injury -a pilot study
}

\author{
T Tasiemski*,1, E Bergström ${ }^{2}$, G Savic $^{2}$ and BP Gardner ${ }^{2}$ \\ ${ }^{1}$ Institute of Rehabilitation, University School of Physical Education, Poznań, Poland; ${ }^{2}$ National Spinal Injuries \\ Centre, Stoke Mandeville Hospital, Aylesbury, Bucks, UK
}

\begin{abstract}
Study design: A pilot postal survey.
Objective: To examine the levels of sporting/recreational activities, education and employment in people with spinal cord injury (SCI) and to assess if involvement in sport and recreation is associated with higher levels of education and employment.

Setting: National Spinal Injuries Centre (NSIC), Stoke Mandeville Hospital, Aylesbury, UK. Methods: Forty-five subjects, who met the following criteria: SCI at level C5 or below, wheelchair dependent, aged between 18 and 50 at the time of injury, injured at least 10 years ago, admitted to the NSIC within 6 months of injury and resident in the UK, completed a 26item postal questionnaire.

Results: Among the 45 subjects $47 \%$ participated in physical activities ( $20 \%$ in sport; $27 \%$ in recreation), $33 \%$ were employed (29\% full-time) and $18.5 \%$ had undergone further education at the time of the survey. Participation in sports as well as employment status decreased after injury $(P<0.01)$ usually as a result of poor access to sports and work facilities. Only $4 \%$ of investigated SCI patients started to practise physical activity after the accident whilst $42 \%$ stopped.

Conclusions: Levels of sporting/recreational activities and employment decreased significantly after injury. No significant correlation was found between sport/recreation involvement and education/employment status. Further investigation with a large number of participants that will enable additional analysis of subgroups, such as level of injury and functional independence, is required.
\end{abstract}

Sponsorship: The study was partly funded by the British Council.

Spinal Cord (2000) 38, $173-184$

Keywords: spinal cord injury; sports; recreation; education; employment

\section{Introduction}

The main objective of sport and recreation activities for spinal cord injured (SCI) persons is physical improvement as well as perfection of wheelchair skills. It has been demonstrated that involvement in sports by wheelchair users improves their rehabilitation outcome, aids the adjustment to their disability, increases their independence, gives them greater selfconfidence, improves their quality of life and gives them aspirations for their further development. ${ }^{1-}$

Gainful employment is an important rehabilitation goal for SCI persons, not only for the individual concerned but also for the state in terms of tax and unemployment benefit. This goal is usually not achieved. $^{8-24}$ Paraplegic persons are more likely to return to work than those with tetraplegia, ${ }^{10,12,15}$

*Correspondence: T Tasiemski, Institute of Rehabilitation, University School of Physical Education, ul. Królowej Jadwigi 27/39, 61-871 Poznań, Poland younger SCI persons than older ones ${ }^{8,10,12,15,18}$ and better educated than less educated ones. ${ }^{10-12,15,18}$ Work experience before SCI, marital status and time since injury are other important factors. ${ }^{8-11}$ Little has been published on the relationship between physical fitness, habitual physical activity and employment status after SCI. ${ }^{18,25}$

In the early decades following the establishment of the National Spinal Injuries Centre (NSIC) at Stoke Mandeville Hospital many of the SCI patients were actively involved in sport. ${ }^{2}$ Employment among the patients of the centre was also high. In recent decades involvement in sports has declined and employment has also fallen.

The purpose of this pilot study was to examine first the levels of sporting/recreational activities, education and employment in SCI people and second to assess if involvement in sport and recreation is associated with higher levels of education and employment. 


\section{Material and methods}

\section{Sample}

The sample consisted of 100 newly injured patients of the NSIC, who were consecutively admitted under the care of the fourth author of this study and who met the following criteria: spinal cord injured at level $\mathrm{C} 5$ or below, wheelchair dependent, aged between 18 and 50 at the time of injury, injured at least 10 years ago, admitted to the NSIC within 6 months of injury and resident in the UK.

These individuals were mailed a package that included a letter of explanation, a questionnaire and a stamped addressed envelope. Completed replies were received from $53(53 \%)$ of individuals within the 30 day limit for returns. Eight questionnaires were excluded as they were inappropriately filled in, leaving $45(45 \%)$ subjects as the study group.

This study was approved by the Aylesbury Vale Health Authority Ethics Committee.

\section{Measures}

The data was gathered from a 26-item questionnaire (see Appendix 1) that covered demographic characteristics, injury data, education before and after injury, employment before and after injury, and details of preinjury and current involvement in sport and recreation. All participants were asked about any medical problems that may have prevented them from pursuing these activities. The current level of independence was also checked. The questionnaire included open questions about important aspects that influenced their sport and vocational involvement.

\section{Analysis}

Due to the small number of investigated SCI persons, paraplegic and tetraplegic subjects were analyzed together and variables were merged as follows: school (primary and secondary) and higher education (college and university); employed (part and full time) and those who did not earn money (student, homemaker, unemployed); sport (high physical activity: $2-7$ times a week) and recreation (low activity: once or less than once a week) and non active group.

Descriptive statistics were used for the presentation of the results. Statistical analysis was performed using SPSS and Sigma-Stat. For comparisons between preinjury and post-injury achievements Z-test for comparing proportions was used and for potential association between sport/recreation and education/ employment, cross-tabulation and Chi-square test. Significance for all statistical analyses was fixed at the 0.01 level of probability.

\section{Results}

The basic demographic and injury characteristics of the 45 patients are presented in Table 1. Eighty per cent of
Table 1 Characteristics of 45 SCI wheelchair users

\begin{tabular}{|c|c|}
\hline Subjec & $\begin{array}{l}(\mathrm{n}=45) \\
\text { Demographic characteristics } \\
(\%)\end{array}$ \\
\hline $\begin{array}{l}\text { Sex } \\
\text { Male } \\
\text { Female }\end{array}$ & $\begin{array}{r}36(80.0) \\
9(20.0)\end{array}$ \\
\hline $\begin{array}{l}\text { Present age } \\
20-30 \text { years old } \\
31-40 \\
41-50 \\
51-65\end{array}$ & $\begin{aligned} 11 & (24.4) \\
17 & (37.8) \\
14 & (31.1) \\
3 & (6.7)\end{aligned}$ \\
\hline $\begin{array}{l}\text { Marital status } \\
\text { Single } \\
\text { Married/living with partner } \\
\text { Divorced/separated } \\
\text { Widowed }\end{array}$ & $\begin{array}{c}22(48.9) \\
20(44.4) \\
3 \quad(6.7) \\
-\end{array}$ \\
\hline $\begin{array}{l}\text { Place of residence } \\
\text { Village } \\
\text { Town } \\
\text { City }\end{array}$ & $\begin{aligned} 15 & (33.3) \\
21 & (46.7) \\
9 & (20.0)\end{aligned}$ \\
\hline $\begin{array}{l}\text { Accommodation } \\
\text { Fully adapted } \\
\text { Accessible for the disabled } \\
\text { Not accessible }\end{array}$ & $\begin{array}{c}17(37.8) \\
26(57.8) \\
2 \quad(4.4) \\
\text { Spinal cord injury }\end{array}$ \\
\hline $\begin{array}{l}\text { Level of injury } \\
\text { Tetraplegic } \\
\text { Paraplegic }\end{array}$ & $\begin{array}{ll}21 & (46.7) \\
24 & (53.3)\end{array}$ \\
\hline $\begin{array}{l}\text { Cause of injury } \\
\text { Road traffic accident } \\
\text { Fall } \\
\text { Sport } \\
\text { Assault } \\
\text { Non traumatic } \\
\text { Others }\end{array}$ & $\begin{array}{rr}22 & (48.9) \\
3 & (6.7) \\
9 & (20.0) \\
1 & (2.2) \\
4 & (8.9) \\
6 & (13.3)\end{array}$ \\
\hline $\begin{array}{l}\text { Age at time of injury } \\
18-30 \text { years old } \\
31-40 \\
41-50\end{array}$ & $\begin{array}{rr}28 & (62.2) \\
14 & (31.1) \\
3 & (6.7)\end{array}$ \\
\hline $\begin{array}{l}\text { Mobility } \\
\text { Manual wheelchair } \\
\text { Electric wheelchair }\end{array}$ & $\begin{array}{l}35(77.8) \\
10(22.2)\end{array}$ \\
\hline $\begin{array}{l}\text { Getting up in the morning } \\
\text { Completely independent } \\
\text { Partially independent } \\
\text { Dependent on others }\end{array}$ & $\begin{array}{l}\text { ssing, washing) } \\
19(42.2) \\
10(22.2) \\
16(35.6)\end{array}$ \\
\hline $\begin{array}{l}\text { Transfer bed, toilet, wheelch } \\
\text { Completely independent } \\
\text { Partially independent } \\
\text { Dependent on others }\end{array}$ & $\begin{aligned} 21 & (46.7) \\
9 & (20.0) \\
15 & (33.3)\end{aligned}$ \\
\hline $\begin{array}{l}\text { Taking bath/shower } \\
\text { Completely independent } \\
\text { Partially independent } \\
\text { Dependent on others }\end{array}$ & $\begin{array}{l}18(40.0) \\
10(22.2) \\
17(37.8)\end{array}$ \\
\hline $\begin{array}{l}\text { Getting to bed at night (und } \\
\text { Completely independent } \\
\text { Partially independent } \\
\text { Dependent on others }\end{array}$ & $\begin{array}{r}\text { sing, washing) } \\
21(46.7) \\
7(15.6) \\
17(37.8)\end{array}$ \\
\hline
\end{tabular}


the subjects were males. More than half $(62 \%)$ were aged between 20 and 40 . About half were married or lived with a partner. Sixty-seven per cent lived in towns or cities. Two persons $(4 \%)$ described their homes as being inaccessible to wheelchairs. Twenty-one $(47 \%)$ were tetraplegic and $24(53 \%)$ paraplegic. The most common cause of injury was road traffic accident $(49 \%)$. At the time of injury 28 persons $(62 \%)$ were relatively young $(18-30)$. Thirty-five $(78 \%)$ used manual wheelchairs and ten $(22 \%)$ were dependent on electric ones. Twenty-seven $(60 \%)$ were at least partially dependent in basic activities of daily living, the average number of hours of help required in each $24 \mathrm{~h}$ being 10 , with the range $0.5-24 \mathrm{~h}$. Eleven patients $(24 \%)$ reported having had medical problems that interfered with their sports/recreation in the last year. Three of them reported continuous medical problems. The duration of medical problems was $12-107$ days in the last year (mean 47).

\section{Sport and recreation}

Involvement in sport and recreation before and after injury is presented in Table 2. The frequency of sporting activities fell from $19(42 \%)$ before the accident to nine $(20 \%)$ at the time of the survey. Of these nine, four were sportsmen, four were involved in recreation and one was non active before the injury.

The frequency of recreational activities also decreased after injury. Nineteen $(42 \%)$ were involved in recreation before the injury compared with 12 $(27 \%)$ at the time of the questionnaire. Amongst these twelve, five practised sport before the accident, six were involved in physical recreation and one was non active.

Of those active after injury, 15 preferred individual sports disciplines and six team games. The most

Table 2 Involvement in sports, education and employment before and after SCI

\begin{tabular}{lcc}
\hline & \multicolumn{2}{c}{ Subjects } \\
& $\begin{array}{c}\text { Before SCI } \\
(\%)\end{array}$ & $\begin{array}{c}\text { After SCI } \\
(\%)\end{array}$ \\
\hline $\begin{array}{lcc}\text { Frequency of sport and physical } \\
\text { Sport }\end{array}$ & $19(42.2)$ & $9(20.0)$ \\
Recreational & $19(42.2)$ & $12(26.7)$ \\
Nil & $7(15.6)$ & $24(53.3)$ \\
Sport discipline & & \\
Individual & $27(60.0)$ & $15(33.3)$ \\
Team games & $11(24.4)$ & $6(13.4)$ \\
None & $7(15.6)$ & $24(53.3)$ \\
Educational achievements & & \\
School & $27(60.0)$ & $22(48.9)$ \\
Higher education & $18(40.0)$ & $23(51.1)$ \\
Employment & & \\
Gainful employment & $39(86.6)$ & $15(33.3)$ \\
Not gainfully employed & $6(13.4)$ & $30(66.7)$ \\
\hline
\end{tabular}

popular sports disciplines were: basketball, archery, swimming, wheelchair racing, weight-lifting, snooker and bowling.

The difference between sport/recreation involvement before and after injury was significant $(P<0.001)$.

The respondents described different reasons for practising sport or other physical activities. For many of them maintenance of good physical condition and improving their upper body strength were the most important factors. The enjoyment of practising sport, competition, improved self-esteem and better weight control were also stated as very important. Other factors mentioned were: decreasing pain, getting out of the house and just keeping active.

The number not active in any kind of physical activity increased from seven $(16 \%)$ before to 24 $(53 \%)$ after the accident. Before injury, of these 24 , ten were involved in sport, nine in recreation and five were non active.

Common reasons for stopping practising sport after the accident were non-existent sporting facilities for the disabled in their locality and dislike of 'traditional' disabled sports like bowls, table tennis, archery etc. Many of the respondents, especially tetraplegic individuals, emphasised the lack of opportunity for practising their favourite sport. For some the fear of further injury, lack of money or lack of time due to professional activities were factors that prevented them from pursuing these activities.

Only two (4\%) from the pre-injury non-active group started to practise some kind of physical activity after the accident whilst $19(42 \%)$ pre-injury active ones gave up sport/recreation after injury.

\section{Education and employment}

Before the accident $27(60 \%)$ had school and $18(40 \%)$ higher education. After the injury five of the 27 $(18.5 \%)$ graduated from college or university (Table 2$)$.

Correlation between sport/recreation and educational status was not statistically significant. Of the $23(51 \%)$ with higher education after injury five $(22 \%$ of the 23) practised sport, six $(26 \%)$ participated in recreation and $12(52 \%)$ were non active. The corresponding figures for the $22(49 \%)$ with only school education post-injury were four $(18 \%$ of the $22)$, six $(27 \%)$ and $12(55 \%)$ respectively.

Thirty-nine $(87 \%)$ were employed at the time of injury. Only $15(33 \%)$ were employed at the time of the questionnaire, $13(29 \%)$ being full-time. The difference between employment status before and after injury was significant $(P<0.001)$.

Several features were described by the participants as adversely influencing their employment. The most frequently reported were: difficulties in finding wheelchair accessible places of work, lack of accessible transport and suitable housing sufficiently close to work. Less frequently reported were: the requirement for full time care and the reluctance of employers to consider a disabled person. 
Correlation between sport/recreation and employment status was not statistically significant. Of the 15 who had gainful employment, two $(13 \%$ of the 15$)$ did sport, five $(33 \%)$ recreation and eight $(54 \%)$ were non active. Among those not gainfully employed seven $(23 \%$ of the 30$)$ were involved in sport, seven $(23 \%)$ in recreation and $16(54 \%)$ were non active.

\section{Discussion}

It has been assessed that the prevalence of SCI in the UK today is $35000 .{ }^{26}$ Our pilot study has shown that over two-thirds of SCI persons of younger working age do not achieve employment following their injury. This represents a very serious deficiency in rehabilitation for the individuals concerned as well as a major drain on the financial resources of the state, both in terms of reduced taxable income as well as increased unemployment benefit payments. It is essential that all reasonable steps are taken to address this.

It has been stated that active involvement by those with SCI in sports and recreation increases their likelihood of employment. ${ }^{18,25,27}$ However there is no published evidence to support this contention in the UK context.

Our study has failed to demonstrate a significant link between post-injury sport/recreation and employment. A much larger study is required to examine this more fully.

One finding of particular concern in our study was the relatively low percentage (18.5) of our sample who improved their education post-injury compared with those of other studies. This merits further investigation.

In the following sections the findings of the key elements of this study, namely sports, education and employment, will be compared with those of other studies.

\section{Sports}

In our study $47 \%$ of SCI patients were involved in some physical activity at the time of the questionnaire (20\% sport and $27 \%$ recreation). This, as well as preferred sports disciplines, is similar to that described elsewhere in the literature. Van Asbeck et $a l^{23}$ identified 48 patients $(41 \%)$ (14 tetraplegics, 34 paraplegics) still active in sport after discharge from hospital. Basketball was played by 11 , table tennis by nine, wheelchair racing by eight, tennis by four and other sports by nine. Sutton ${ }^{21}$ described participation in sport as the most popular leisure activity in $24(32 \%)$ out of 75 subjects.

In our study, the most important reason given for practising sport was to improve health, and the most common reason for not playing sport was lack of wheelchair access. Richards ${ }^{20}$ found that $33 \%$ of SCI patients, in particular tetraplegics, expressed frustration at being unable to pursue their favourite sport.

\section{Education}

In our study, only $18.5 \%$ improved their education following injury. This contrasts with other studies which report much higher level of post-injury educational improvement. For example, El Ghatit ${ }^{10,11}$ reported $40 \%$ and Weidman ${ }^{24} 43 \%$.

Comparison with other studies is not always straightforward. For example, Kruse et al ${ }^{16}$ did not give pre-injury education achievements in his sample.

\section{Employment}

The percentage $(33 \%)$ of SCI persons engaged in gainful employment in our study is broadly similar to that of others ${ }^{9,10,13-23,28}$ even though these were from different countries where employment opportunities and unemployment benefits differed from those in Britain. The results of these studies, in comparison with ours, are given in Table 3.

However, more precise comparison is prevented by the dissimilarity of the patient characteristics and methodology of the different studies. Eleven authors did not mention a retired group. ${ }^{9,10,12,14-19,21,28}$ Richards ${ }^{19,20}$ did not mention ages. El Ghatit ${ }^{10}$ and Kruse et al $^{16}$ gave only the mean age of evaluated subjects. De Vivo et $a l^{9}$ had patients from $13-59$ years of age. Noreau ${ }^{18}$ had patients in the same age range $(13-59)$, but only those free of any major medical complications that could influence physical working capacity. Kiwerski ${ }^{14}$ had persons aged 18-60. Nakajima ${ }^{17}$ had patients from 16 to 73 . Sutton et $a l^{21}$ interviewed only patients of working age. Van Asbeck et $a l,{ }^{23}$ who reported a very low percentage of unemployed persons $(14.5 \%)$, treated voluntary work $(8.5 \%)$ as employment which in other studies was considered a hobby. Krause, ${ }^{15}$ who described a high percentage of employed people $(48 \%)$, had only welleducated subjects. Lovell et $a l^{28}$ interviewed athletes with SCI from several different countries including Britain (37 participants/eight employed), Egypt (13/0), Iran (14/0), Israel (6/2), Jordan (6/1), Poland (8/0), South Africa (7/7), USA (7/2) and Others (20/11).

In our study the main reason given for failure to be in employment was the absence of satisfactory wheelchair access. This contrasted with other studies. In Weidman's study, ${ }^{24} 27 \%$ stated that they did not feel adequately trained for the job market. Other factors cited were inadequate transport, chronic pain and 'lack of desire'. In El Ghatit's study ${ }^{10}$ the most frequent reasons given were inability to hold a steady job because long hours in the wheelchair caused pressure sores, inability to find a suitable job, domestic reasons and frequent hospital readmissions.

The finding of our study that post-injury employment decreased and education increased relative to pre-injury, is similar to that of Taricco et al. 22 Although two other studies recorded the level of pre-injury employment, comparison was not possible, because the data was recorded differently. ${ }^{9,18}$ 
Table 3 Employment status of SCI persons post-injury

\begin{tabular}{|c|c|c|c|c|c|c|}
\hline Author (Country) & $\begin{array}{l}\text { Gainfully } \\
\text { employed }\end{array}$ & Student & Household & Unemployed & Retired & Total \\
\hline De Vivo $^{9}$ (USA) & $46(30 \%)$ & $16(10 \%)$ & $13(8 \%)$ & $79(51 \%)$ & - & 154 \\
\hline El Ghatit ${ }^{10}$ (USA) & $179(23 \%)$ & - & - & $380(50 \%)$ & - & 760 \\
\hline Geisler $^{12}$ (Canada) & $551(46 \%)$ & - & - & - & - & 1204 \\
\hline Goldberg $^{13}$ (USA) & $5(21 \%)$ & $1(4 \%)$ & - & $17(71 \%)$ & $1(4 \%)$ & 24 \\
\hline Kiwerski ${ }^{14}$ (Poland) & $66(35 \%)$ & $9(5 \%)$ & - & $116(60 \%)^{* *}$ & - & 191 \\
\hline Krause $^{15}$ (USA) & $137(48 \%)$ & - & - & - & - & 286 \\
\hline Kruse $^{16}$ (USA) & $117(30 \%)$ & - & - & - & - & 391 \\
\hline Nakajima $^{17}$ (Japan) & $271(28 \%)$ & - & - & - & - & 926 \\
\hline Noreau $^{18}$ (Canada) & $39(65 \%)$ & - & - & $21(35 \%)$ & - & 60 \\
\hline Richards $^{19}(\mathrm{UK})$ & $23(23 \%)$ & $14(14 \%)$ & $15(15 \%)$ & $48(48 \%)$ & - & 100 \\
\hline Richards $^{20}$ (Australia) & $46(29 \%)$ & $14(7 \%)$ & $7(4 \%)$ & $86(53 \%)$ & $8(5 \%)$ & 161 \\
\hline Sutton $^{21}(\mathrm{UK})$ & $13(37 \%)$ & - & - & - & - & 35 \\
\hline Taricco $^{22}$ (Italy) & $31(32 \%)$ & $15(16 \%)$ & $13(13 \%)$ & $25(26 \%)$ & $13(13 \%)$ & 97 \\
\hline Van Asbeck ${ }^{23}$ (Netherlands) & $38(32 \%)$ & $6(5 \%)$ & $43(37 \%)$ & $27(23 \%)^{*}$ & $3(3 \%)$ & 117 \\
\hline Lovell $^{27}(\mathrm{UK})$ & $31(26 \%)$ & - & - & - & - & 118 \\
\hline This study (UK) & $15(33 \%)$ & $3(7 \%)$ & $2(4 \%)$ & $25(56 \%)$ & - & 45 \\
\hline
\end{tabular}

$* 27(23 \%)=17(14.5 \%)$ unemployment $+10(8.5 \%)$ voluntary work. $* * 116(60 \%)=96(50 \%)$ disability pension $+20(10 \%)$ maintained by the family

In our study we found no significant correlation between sports involvement and education/employment activities. A larger number is required to examine this more fully, because the findings of other authors conflict in this area. Curtis et $a l^{25}$ studied the relationship between sports involvement and vocational status in SCI persons and found that there was a greater involvement in work/educational activities in the athletic group. In contrast, Foreman et $a l^{27}$ showed that although more participants in sport were currently employed and studying than were non participants, the difference was not significant. Noreau $^{18}$ found a positive relationship between physical fitness and gainful employment in persons with paraplegia. There were no significant differences in physical fitness or physical activity between workers with sedentary as opposed to physically demanding jobs.

\section{Limitations of the study}

Due to the small number of SCI people in our study it was impossible to divide them by neurological level. Further investigation with a large number of participants will enable additional analysis of subgroups, such as level of injury and functional independence.

\section{Conclusions}

(1) Participation in sport and recreation activities decreased from $84 \%$ pre-injury to $47 \%$ after injury $(P<0.01)$. The most frequently reported reason was poor wheelchair access.

(2) Only two (4\%) people not physically active preinjury started practising some kind of activity after the accident, whilst $19(42 \%)$ of those actively involved in sport/recreation before injury stopped.
(3) After injury $18.5 \%$ patients improved their education. In spite of this the employment status dramatically decreased from $87 \%$ to $33 \%$ $(P<0.01)$. The most frequent factor identified in reducing gainful employment was inadequate access and transport.

(4) No significant correlation was found between sport/recreation involvement and education/employment status.

(5) To enable more detailed analysis of subgroups, a larger study is required.

\section{References}

1 Guttmann L. Sport and the spinal cord sufferer. Nursing Mirror Midwives $J$ 1975; 141: 64-65.

2 Guttmann L. Significance of sport in rehabilitation of spinal paraplegics and tetraplegics. JAMA 1976; 236: 195-197.

3 Jackson RW, Davis GM. The value of sports and recreation for the physically disabled. Orthopaed Clin North Am 1983; 14: 301 315.

4 Jackson RW. Sport for the spinal paralysed person. Paraplegia 1987; 25: 301-304.

5 Shephard RJ. Benefits of sport and physical activity for the disabled: implications for the individual and for society. Scand $J$ Rehabil Med 1991; 23: 51-59.

6 Stotts KM. Health maintenance: paraplegic athletes and nonathletes. Arch Phys Med Rehabil 1986; 67: 109-114.

7 Tasiemski T. Skiing of the disabled: recreation, rehabilitation or sports achievement? Based on the example of the National Ability Center. Postepy Rehabilitacji 1996; 10: $141-146$.

8 DeVivo MJ, Fine PR. Employment status of spinal cord injured patients 3 years after injury. Arch Phys Med Rehabil 1982; 63: $200-203$

9 DeVivo MJ, Rutt RD, Stover SL, Fine PR. Employment after spinal cord injury. Arch Phys Med Rehabil 1987; 68: 494-498.

10 El Ghatit AZ, Hanson RW. Variables associated with obtaining and sustaining employment among spinal cord injured males: a follow-up of 760 veterans. J Chronic Dis 1978; 31: 363-369. 
11 El Ghatit AZ, Hanson RW. Educational and training levels and employment of spinal cord injured patient. Arch Phys Med Rehabil 1979; 60: $405-406$.

12 Geisler WO, Jousse AT, Wynne-Jones M. Vocational reestablishment of patients with spinal cord injury. Medical Services Journal Canada 1966; 22: 698-709.

13 Goldberg RT, Freed MM. Vocational development of spinal cord injury patients: an 8-year follow-up. Arch Phys Med Rehabil 1982; 63: $207-210$

14 Kiwerski J, Chrostowska T. Social and professional evaluation of para and tetraplegics. Paraplegia 1982; 20: 97-102.

15 Krause JS. Employment after spinal cord injury. Arch Phys Med Rehabil 1992; 73: 163 - 169

16 Kruse D, Krueger A, Drastal S. Computer use, computer training and employment, outcomes among people with spinal cord injuries. Spine 1996; 21: $891-896$.

17 Nakajima A, Honda S. Physical and social condition of rehabilitated spinal cord injury patients in Japan: a long-term review. Paraplegia 1988; 26: 165-176.

18 Noreau L, Shephard RJ. Return to work after spinal cord injury: the potential contribution of physical fitness. Paraplegia 1992; 30: $563-572$.

19 Richards B. An evaluation of home care after spinal cord injury. Paraplegia 1975; 12: $263-267$.

20 Richards B. A social and psychological study of 166 spinal cord injured patients from Queensland. Paraplegia 1982; 20: 90-96.
21 Sutton RA et al. Review of the social situation of paraplegic and tetraplegic patients rehabilitated in the Hexham Regional Spinal Injury Unit in the North of England over the past four years. Paraplegia 1982; 20: $71-79$.

22 Taricco $\mathrm{M}$ et al. The social and vocational outcome of spinal cord injury patients. Paraplegia $1992 ; 30: 214-219$

23 Van Asbeck FW, Raadsen H, Van de Loo ML. Social implications for persons 5-10 years after spinal cord injury. Paraplegia 1994; 32: 330-335.

24 Weidman CD, Freehafer AA. Vocational outcome in patients with spinal cord injury. J Rehabil 1981; 43: 63-65.

25 Curtis KA et al. Health, vocational, and functional status in spinal cord injured athletes and nonathletes. Arch Phys Med Rehabil 1986; 67: $862-865$.

26 Smith M. Making the difference-efficacy of specialist versus nonspecialist management of spinal cord injury. London: Spinal Injuries Association 1999, pp $12-15$

27 Foreman PE, Cull J, Kirkby RJ. Sports participation in individuals with spinal cord injury: demographic and psychological correlates. Int J Rehabil Res 1997; 20: 159-168.

28 Lovell ME, Thomas AF, Shakesby R, McNeilly P. Social adjustment and rehabilitation in international competitors with spinal injuries sustained in military service. Disabil Rehabil 1997; 19: $92-96$ 
QUESTIONNAIRE (please tick [ ] chosen answers)

Name \&

Surname

\section{PERSONAL DETAILS}

1. Sex

1.1. Male [ ]

1.2. Female [ ]

\section{Present age}

2.1. 20 - 30 years old [ ]

2.2. $31-40 \quad[]$

2.3. $41-50 \quad[$ ]

2.4. $51-65[]$

\section{Place of living}

3.1. Village [ ]

3.2. Town [ ]

3.3. City [ ]

\section{Marital status}

4.1. Single [ ]

4.2. Married / living with partner [ ]

4.3. Divorced / separated [ ]

4.4. Widowed [ ]

\section{Accommodation}

5.1. Fully adapted [ ]

5.2. Accessible for the disabled [ ]

5.3. Not accessible [ ] 


\section{SPINAL CORD INJURY}

6. Level of injury

6.1. Tetraplegic [ ]

6.2. Paraplegic [ ]

6.3. Please state your exact level of injury (if you know it)

\section{Cause of injury}

7.1. Road traffic accident [ ]

7.2. Fall from height [ ]

7.3. Sport accident [ ]

7.4. Assault [ ]

7.5. Nontraumatic [ ]

7.6. Others (please state)

8. Age at time of injury

8.1. 18 - 30 years old [ ]

8.2. $31-40 \quad[]$

8.3. $41-50 \quad[]$

\section{BEFORE INJURY}

\section{Educational achievements}

9.1. Primary [ ]

9.2. Secondary [ ]

9.3. College [ ]

9.4. University degree [ ]

9.5. Additional qualifications (please state)

9.6. Occupation (please state) 
10. Employment

10.1. Student [ ]

10.2. Employed part time [ ]

10.3. Employed full time [ ]

10.4. House work [ ]

10.5. Unemployed [ ]

10.6. If employed, what kind of job was it (please state)

\section{Sport discipline}

11.1. Individual [ ]

11.2. Team games [ ]

11.3. Your favourite sport (please state).

11.4. Please list all other sports you practised

\section{Frequency of sport and physical activity}

12.1. Regular training (5 - 7 a week) [ ]

12.2. High activity (2 - 4 a week) [ ]

12.3. Low activity (once a week) [ ]

12.4. Less than once a week [ ]

12.5. Non active [ ]

\section{AFTER INJURY}

\section{Educational achievements}

13.1. Primary [ ]

13.2. Secondary [ ]

13.3. College [ ]

13.4. University degree [ ]

13.5. Additional qualifications (please state)

13.6. Occupation (please state) 


\section{Employment}

14.1. Student [ ]

14.2. Employed part time [ ]

14.3. Employed full time [ ]

14.4. House work [ ]

14.5. Unemployed [ ]

14.6. If employed, what kind of job is it (please state)

15. Sport discipline

\subsection{Individual [ ]}

15.2. Team games [ ]

15.3. Your favourite sport (please state).

15.4. Please list all other sports you practise.

16. Frequency of sport and physical activity

16.1. Regular training (5 - 7 a week) [ ]

16.2. High activity (2 - 4 a week) [ ]

16.3. Low activity (once a week) [ ]

16.4. Less than once a week [ ]

16.5. Non active [ ]

17. Have you had any medical problems that prevented you from pursuing these activities?

17.1. Yes [ ]

17.2. No [ ]

17.3. If yes, how many days in the last year? days 


\section{CURRENT LEVEL OF INDEPENDENCE}

18. Mobility

18.1. Manual wheelchair [ ]

18.2. Electric wheelchair [ ]

19. Getting up in the morning (dressing, washing)

19.1. Completely independent [ ]

19.2. Partially independent [ ]

19.3. Dependent on others [ ]

20. Transfer bed, toilet, wheelchair etc.

20.1. Completely independent [ ]

20.2. Partially independent [ ]

20.3. Dependent on others [ ]

\section{Taking bath / shower}

21.1. Completely independent [ ]

21.2. Partially independent [ ]

21.3. Dependent on others [ ]

22. Getting to bed at night (undressing, washing)

22.1. Completely independent [ ]

22.2. Partially independent [ ]

22.3. Dependent on others [ ]

23. How many hours of help on average do you need in each 24 hour period? 


\section{FINAL QUESTIONS (BLOCK CAPITALS)}

24. If you stopped practising sport after your injury, please state the $\operatorname{reason}(s)$.

25. If you started practising sport after your injury, please state the $\operatorname{reason}(s)$.

26. If there are any important aspects which influence your employment please indicate them below. (In particular, aspects such as housing, personal factors, economic factors and levels of care should be considered.)

Thank you very much for taking time to answer this questionnaire. 